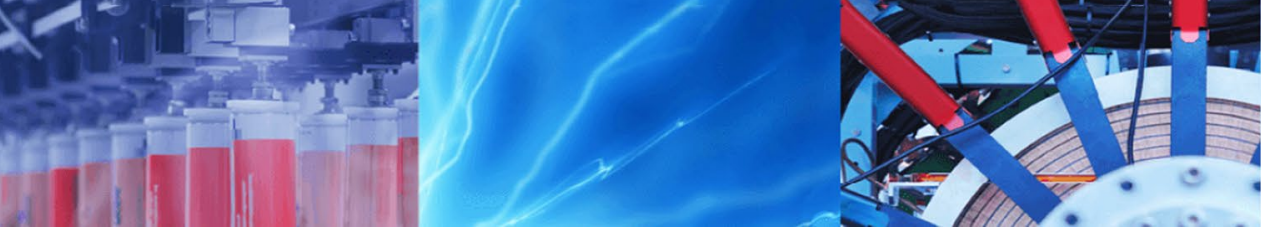

Research Article

\title{
Facile, cost-effective and eco-friendly synthesis of carbonyl-rich partially reduced graphene oxide using glucose as a sole precursor
}

\author{
K. C. Sunil ${ }^{1}$ D $\cdot$ Saritha Suvarna ${ }^{2} \cdot$ Rajesha K. Nairy $^{3} \cdot$ G. Chethan $^{1} \cdot$ M. S. Mustak ${ }^{4} \cdot$ Narayana Yerol $^{1}$
}

Received: 1 April 2020 / Accepted: 23 June 2020 / Published online: 3 July 2020

(c) Springer Nature Switzerland AG 2020

\begin{abstract}
Industrial applications of reduced graphene oxide ( $\mathrm{rGO}$ ) demand simple, cost-effective, eco-friendly and scalable synthesis methods. Besides, some applications desire rGO with specific functional groups. Therefore, we employed a simple one-step hydrothermal method to produce carbonyl functional group rich partially reduced graphene oxide using glucose as a sole precursor. We characterized the sample by XRD, XPS, FTIR, UV-Vis, Raman, SEM and DLS techniques. The characterization confirmed the formation of peripheral carbonyl-rich partially reduced graphene oxide. The sample contains 2-3 layers and has moderate zeta potential. We also proposed a plausible reaction mechanism to provide insight into the structural evolution. The reaction involved 2 sub-stages: (1) conversion of glucose into carbonyl-rich graphene oxide through successive chemical modifications, (2) partial reduction of formed graphene oxide by remaining unreacted glucose. Here, glucose acted as both precursor as well as reducing agent. As glucose is the sole material in the process and the reaction is carried out at a moderate temperature, the method is eco-friendly and cost-effective. The carbonyl functional groups present in the sample enable further functionalization and also provide good dispersibility in water which makes them useful in biomedical and water treatment related applications.
\end{abstract}

Keywords Reduced graphene oxide · Glucose · Hydrothermal synthesis · Carbonyl-rich · Bottom-up synthesis · Graphene oxide

\section{Introduction}

Reduced graphene oxide ( $\mathrm{rGO}$ ), the product of oxidation and subsequent reduction of graphite [1-3], serves as a replacement to the pristine graphene in industrial applications owing to its large-scale production capabilities $[4,5]$. Though it supports scalable production, it compromises in quality due to the presence of defects and oxygen functional groups (epoxy and hydroxyl groups on basal plane and carbonyl and carboxylic groups at the plane edge) [6] incepted during oxidation/reduction process. Thus, it is not widely commercialized in electronics and other energy-related applications even after these many years of discovery. However, not all the graphene-related applications require high-quality $\mathrm{rGO}$ and some application even desires $\mathrm{rGO}$ with specific defect types [7] and functional groups, e.g. Drug delivery [8], Water treatment $[9,10]$ and Microwave absorption [11].

In addition, industrial applications of rGO demand a simple, fast, cost-effective and eco-friendly synthesis method [12]. Conventionally, rGO is synthesized in 3 steps via a top-down approach. (1) Oxidation of graphite into graphite oxide, (2) exfoliation of graphite oxide into graphene oxide and (3) reduction of graphene oxide [2]. Quality of the rGO largely depends on the adopted reduction method. Most commonly used reduction methods are

$\triangle$ Narayana Yerol, narayanay@yahoo.com | 'Department of Physics, Mangalore University, Mangalagangothri, Mangalore 574 199, India. ${ }^{2}$ Department of Studies in Physics, DR NSAM FG College, Nitte, Karkala, Mangalore 574 110, India. ${ }^{3}$ Department of Physics, P.C. Jabin Science College, Hubballi 580 031, India. ${ }^{4}$ Department of Applied Zoology, Mangalore University, Mangalagangothri, Mangalore 574 199, India. 
chemical, thermal and hydrothermal reduction. Chemical reduction is a largely practiced method due to its ability for mass production of desired quality rGO. However, it involves hazardous chemicals like hydrazine or sulfonate $[13,14]$, whose residues affect the structure and properties of the prepared rGO and makes it toxic and noneco-friendly. Whereas, thermal reduction doesn't use any toxic chemicals but it requires high thermal energy (temperature of $900-1000^{\circ} \mathrm{C}$ ) and also it introduces undesired defects [15].

In comparison, hydrothermal reduction offers a simple, fast, eco-friendly route as it utilizes only water and sometimes a mild reducing agent [16-18]. Furthermore, hydrothermal experimental set up contains a Teflon autoclave and a furnace that suits industrial large-scale production. However, like chemical and thermal methods, hydrothermal reduction itself is a separate step along with oxidation and exfoliation, which makes the process timeconsuming. On the other hand, bottom-up hydrothermal synthesis is simple and can serve as a better alternative. In this method, a carbon source is subjected to carbonization via hydrothermal treatment to obtain graphene-related materials $[19,20]$.

Recently, glucose was proposed as a carbon source to produce graphene oxide [21]. Under high temperature and pressure, glucose gets converted into graphene oxide through successive chemical modification. Furthermore, glucose is also shown to reduce graphene oxide under hydrothermal conditions. Interestingly, glucose selectively reduces hydroxyl and epoxide groups of the graphene oxide whereas carbonyl functional groups remain unreduced $[22,23]$. This suggests that glucose can transform into carbonyl-rich partially reduced graphene oxide if subjected to sufficiently long hydrothermal treatment. However, the reaction temperature should not exceed $160^{\circ} \mathrm{C}$ as it results in carbon spheres formation [24]. This process is cost-effective and eco-friendly because it involves glucose, an abundant material and is carried out at a moderate temperature. Moreover, the carbonyl functional groups present in the sample offer a possibility for further functionalization and also provide good dispersibility in water which makes them useful in biomedical [25-27] and water treatment related applications [9].

In this context, the present study describes a simple, onestep, cost-effective, eco-friendly synthesis of carbonyl-rich partially reduced graphene oxide by hydrothermal method using glucose as a sole precursor as well as the reducing agent. The study discusses the detailed characteristics of the synthesized rGO evaluated using X-ray Diffraction (XRD), $X$-ray Photoelectron Spectroscopy (XPS), Fourier Transform Infrared Spectroscopy (FTIR), UV-Vis Spectroscopy, Raman Spectroscopy, Scanning Electron Microscopy (SEM), and Dynamic Light Scattering (DLS) characterization techniques.
We have also proposed a plausible reaction mechanism for the formation of carbonyl-rich partial reduced graphene oxide to provide insight into the structural evolution.

\section{Experimental section}

\subsection{Materials}

$\beta-D$ glucose was purchased from Sisco Research Laboratories Pvt. Ltd, India and used as received. Double distilled water was used throughout the process.

\subsection{Synthesis of carbonyl-rich partially reduced graphene oxide}

Carbonyl-rich partially reduced graphene oxide was prepared by the hydrothermal method with modified reaction parameters [19-21]. Briefly, $50 \mathrm{ml}$ of $0.5 \mathrm{M}$ glucose solution was stirred for $30 \mathrm{~min}$. Later, the solution was transferred to $100 \mathrm{ml}$ Teflon autoclave and heated in a hot air oven at $160^{\circ} \mathrm{C}$ for $12 \mathrm{~h}$. Then, the sample was allowed to cool to room temperature. After that, the sample was washed 3 times with double distilled water and dried in a hot air oven at $60^{\circ} \mathrm{C}$ for $48 \mathrm{~h}$. Finally, the as-prepared sample was stored in a desiccator.

\subsection{Characterization}

The X-ray Diffraction (XRD) patterns were recorded by Rigaku Miniflex600 X-Ray diffractometer with Cu Ka radiation $\left(\lambda=1.54 \mathrm{~A}^{\circ}\right)$ at a scan rate of $2^{\circ} / \mathrm{min}$ in scan range $5^{\circ}-45^{\circ}$. The X-ray Photoelectron Spectroscopy (XPS) analysis was performed on KRATOS Axis Ultra DLD system with a monochromatic Al Ka X-ray source (1486.6 eV). Fourier Transform Infrared (FTIR) spectra were collected using SHIMADZU IRPrestige-21 FTIR spectrometer in wavenumber range $4000-500 \mathrm{~cm}^{-1}$. UV-Vis absorption spectra were recorded using SHIMADZU 1800 UV-Vis spectrometer in the wavelength range of $190-800 \mathrm{~nm}$. Raman spectroscopy measurements were taken using HORIBA LabRAM HR Raman microscope with a $532 \mathrm{~nm}$ laser. Scanning Electron Microscope (SEM) images were taken by Carl Zeiss Sigma field-emission scanning electron microscope (FESEM). Particle size and Zeta potential were measured by BROOKHAVEN Zeta PALS Zeta potential analyzer utilizing phase analysis of Dynamic Light Scattering (DLS).

\section{Results and discussion}

The crystalline structure of the as-prepared sample was studied by XRD (Fig. 1a) [28]. In Fig. 1a, broad diffraction peak at $2 \theta=22.5^{\circ}$ corresponds to the (002) reflection 
plane. The flake size $D$ and interlayer spacing $d_{002}$ of the sample calculated using Scherrer Formula and Bragg's Law are $5.91 \mathrm{~A}^{\circ}$ and $3.95 \mathrm{~A}^{\circ}$, respectively. The average number of layers per single $\mathrm{rGO}$ flake thus calculated using $\mathrm{d}_{002}$ and $D$ is 2.5 . The broad diffraction peak at $22.5^{\circ}$ confirms the formation of reduced graphene oxide [20]. The broadening of the peak is due to the shorter stack height of the produced sample.

The elemental composition and chemical environment of the elements in the sample were determined by XPS [29]. Figure $1 \mathrm{~b}$ confirms the presence of carbon and oxygen elements in the sample through the characteristic binding energy peaks at $\sim 285 \mathrm{eV}(\mathrm{C} 1 \mathrm{~s})$ and $\sim 531 \mathrm{eV}(\mathrm{O} 1 \mathrm{~s})$, respectively. In order to study the oxygen functionalization in the sample, the high-resolution XPS core-level spectra of $\mathrm{C} 1 \mathrm{~s}$ and $01 \mathrm{~s}$ were deconvoluted and corresponding oxygen functional groups were assigned based on theoretical prediction of core-level shift [30].

Figure 1c shows the $\mathrm{C} 1 \mathrm{~s}$ core-level XPS spectra of the sample. A well-defined intense peak at binding energy
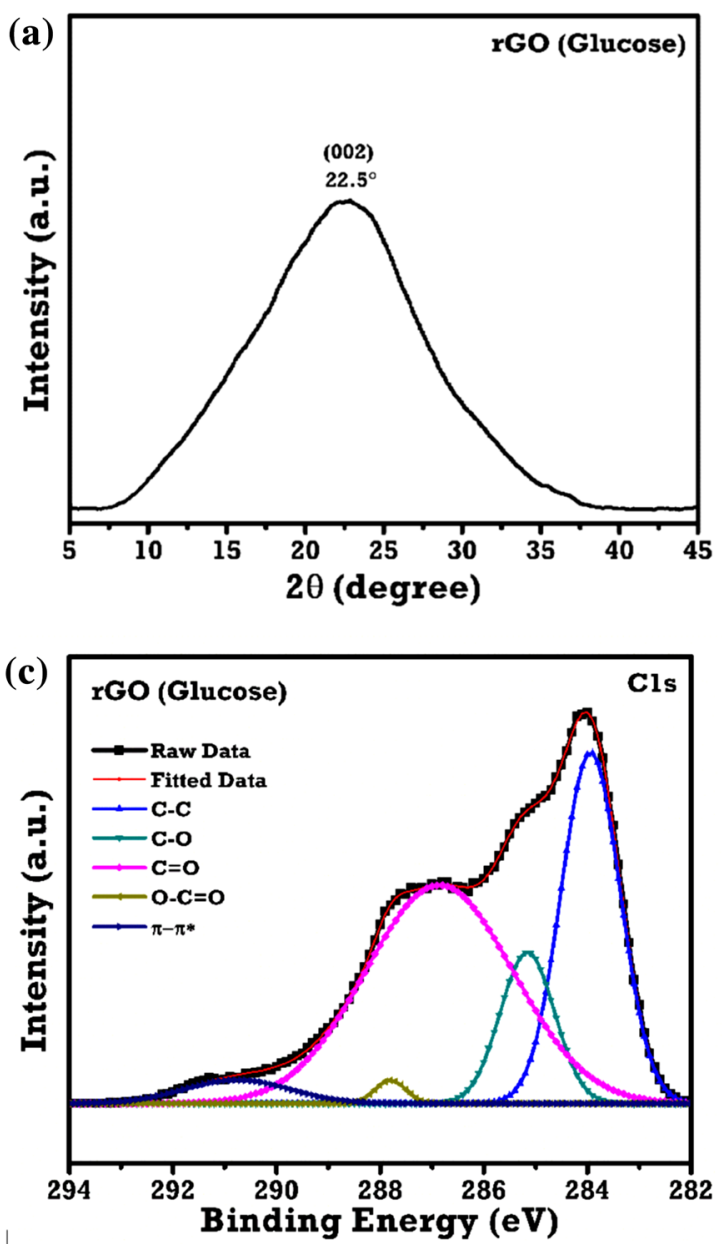

$284 \mathrm{eV}$ corresponds to the unoxidized $s p^{2}$ carbon with $\mathrm{C}-\mathrm{C} / \mathrm{C}=\mathrm{C}$ in the aromatic rings of $\mathrm{rGO}$. The binding energies of deconvoluted peaks at $285.2 \mathrm{eV}, 286.9 \mathrm{eV}$, and $287.8 \mathrm{eV}$ are assigned to $s p^{3}$ carbon of $\mathrm{C}-\mathrm{O}-\mathrm{C} / \mathrm{C}-\mathrm{OH}$ (epoxy/hydroxy), $\mathrm{C}=\mathrm{O}$ (carbonyl) and $\mathrm{HO}-\mathrm{C}=\mathrm{O}$ (carboxylic) [16] oxygen functional groups, respectively. The chemical shifts of the $\mathrm{C} 1 \mathrm{~s}$ to higher binding energies are due to the attachment of more electronegative oxygen functional groups. The $291 \mathrm{eV}$ component stems from the shake-up satellite peak $\left(\pi-\pi^{*}\right)$ of $s p^{2}$ carbon bonds [31]. Figure 1d shows the O1s XPS spectra of $\mathrm{rGO}$. The presence of $\mathrm{C}-\mathrm{O}$, $\mathrm{C}=\mathrm{O}$ and $\mathrm{O}-\mathrm{C}=\mathrm{O}$ functional groups were again confirmed by the deconvoluted peaks centered at $533.5 \mathrm{eV}, 531.2 \mathrm{eV}$ and $530.2 \mathrm{eV}$ [16], respectively.

The XPS result (Fig. 1c, d) clearly shows that the present sample contains high amount of carbonyl functional groups compared to hydroxyl, epoxy and carboxylic groups. The $\mathrm{C} / \mathrm{O}$ ratio of the sample is 2.1 , which suggests the formation of graphene oxide [21] (for $\mathrm{rGO} C / \mathrm{O}>7$ [30]). Whereas, XRD result suggested the formation of $\mathrm{rGO}$ and
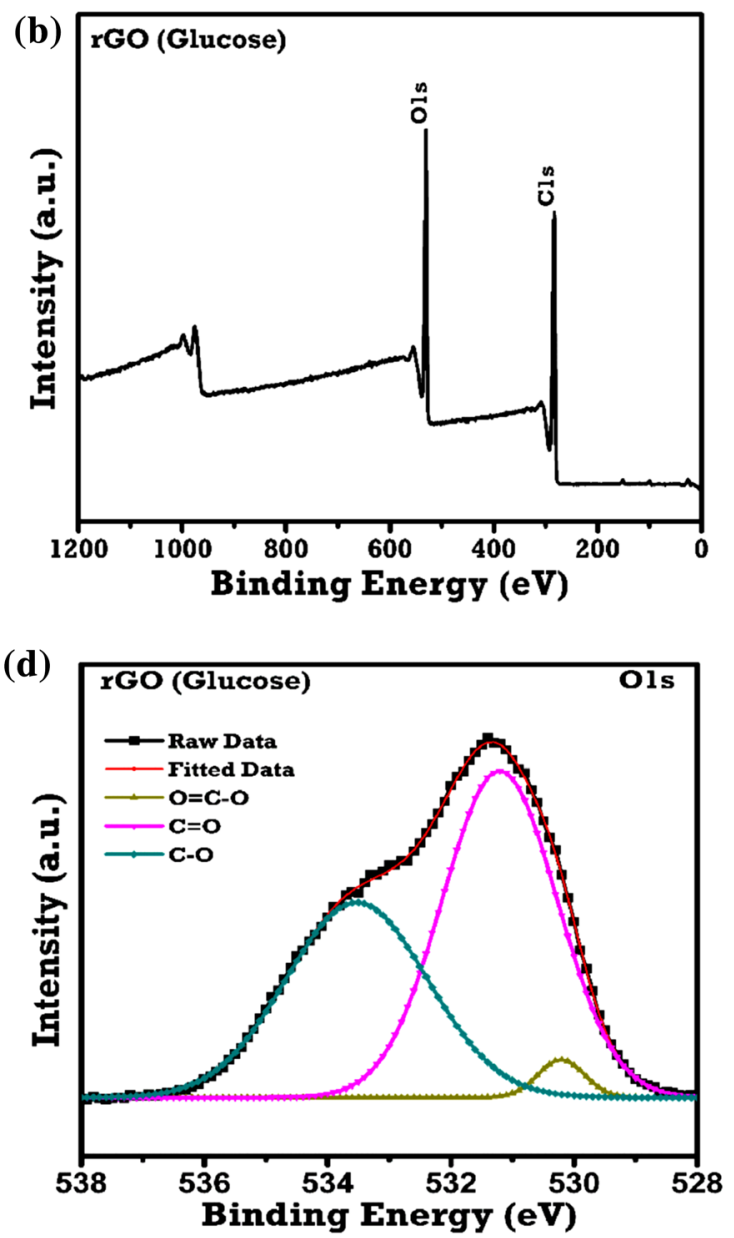

Fig. 1 a XRD pattern and XPS, b survey spectrum, deconvoluted, $\mathbf{c}$ C1s and $\mathbf{d}$ O1s core level spectrum of carbonyl-rich partially reduced graphene oxide 
we also didn't observe any diffraction peak around $10^{\circ}$, which is generally observed in the case of oxygen-rich graphene derivatives [32]. The contrast in XPS and XRD results is because the majority of the oxygen in the sample is of carbonyl functional groups that exist at the plane edge. Glucose and the hydrothermal method itself selectively reduce hydroxyl and epoxy groups on the basal plane of intermediate graphene oxide leaving carbonyl groups unreduced $[22,23,33]$.

The FTIR characterization also confirmed the presence of oxygen functional groups along with $\mathrm{H}_{2} \mathrm{O}$ and $\mathrm{CO}_{2}$ released during reduction. In the FTIR spectrum (Fig. 2a), strong characteristic peak at $1534 \mathrm{~cm}^{-1}$ due to $C=C$ stretching skeletal vibrations of aromatic domains [32] and peak at $1680 \mathrm{~cm}^{-1}$ corresponding to $C=O$ stretching vibrations in carbonyl groups [10] confirms the formation of carbonyl-rich partially reduced graphene oxide. Peaks at $1305 \mathrm{~cm}^{-1}, 1207 \mathrm{~cm}^{-1}$, and $1028 \mathrm{~cm}^{-1}$ are due to $\mathrm{C}-\mathrm{O}$ bending vibrations, epoxy $\mathrm{C}-\mathrm{O}-\mathrm{C}$ stretching vibrations and alkoxy C-O stretching vibrations [20], respectively. The weak broad peak from 3491 to $2920 \mathrm{~cm}^{-1}$ is due to
$\mathrm{O}-\mathrm{H}$ stretching vibrations in hydroxyl groups present on the basal plane and of intercalated free $\mathrm{H}_{2} \mathrm{O}$ molecules [20]. Residual $\mathrm{CO}_{2}$ adsorbed on to the sample results in a small peak at $2333 \mathrm{~cm}^{-1}$ [34]. $1403 \mathrm{~cm}^{-1}$ peak is attributed to $\mathrm{O}-\mathrm{H}$ bending vibrations incurred by the angular deformation of water adsorbed on the sample [32]. FTIR result (Fig. 2a) also clearly shows the presence of a high amount of $\mathrm{C}=\mathrm{O}$ functional groups through corresponding intense peak at $1680 \mathrm{~cm}^{-1}$ which is consistent with XPS.

The extent of formation and reduction of graphene oxide is evaluated using UV-Vis spectroscopy. Figure $2 b$ shows the UV-Visible absorption spectrum of the sample. In the spectrum, absorbance peaks at $225 \mathrm{~nm}$ and $285 \mathrm{~nm}$ corresponds to $\pi-\pi^{*}$ transition of $s p^{3}$ and $s p^{2}$ hybridized carbon bonds, respectively [35]. $s p^{3}$ carbon atoms confirm the presence of oxygen functional groups. This result is in agreement with XPS and FTIR results.

Raman spectroscopy characterizes the structure and disorder/defect in graphene-related materials. In a typical Raman spectrum of $\mathrm{rGO}$, the position and relative intensity $\left(I_{D} / I_{G}\right)$ of $D$ and $G$ band determine the quality
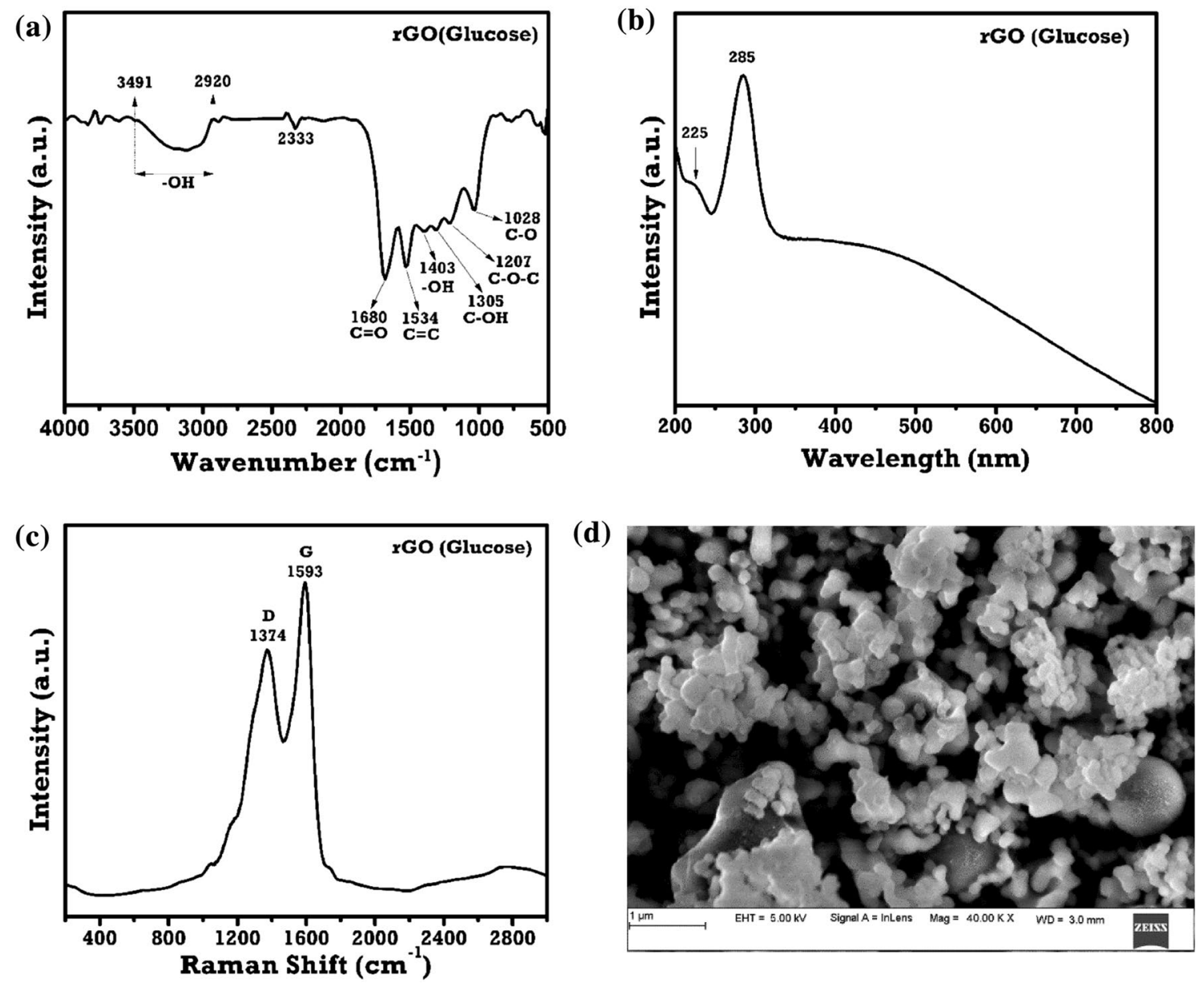

Fig. 2 a FTIR, b UV-Vis, c Raman spectrum and d SEM image of carbonyl-rich partially reduced graphene oxide 
of the sample as well as the efficiency of the reduction method [36]. D band $\left(\sim 1350 \mathrm{~cm}^{-1}\right)$ measures the degree of disorder/defect in the sample and it arises from the breathing mode of K-point phonons of $A_{1 g}$ symmetry in $s p^{3}$ carbon atoms associated with oxygen functional groups. $\mathrm{G}\left(\sim 1575 \mathrm{~cm}^{-1}\right)$ is the characteristic band of graphene materials and it arises from the first-order scattering of the $E_{2 g}$ phonons of $s p^{2}$ carbon atoms of $C-C / C=C$ bonds [37]. In Fig. 2c, the blueshift of D band $\left(1374 \mathrm{~cm}^{-1}\right)$ and $G$ band $\left(1593 \mathrm{~cm}^{-1}\right)$ can be attributed to the induced structural defects by oxygen functional groups. The $I_{D} /$ $I_{G}$ of the sample is 1.39 . The relatively high $I_{D} / I_{G}$ ratio is due to the smaller average size of the sample resulted from high temperature and pressure during hydrothermal synthesis.

The morphology of the sample was investigated using FE-SEM. SEM image (Fig. 2d) shows a thick flake-like structure formation which may have resulted from the agglomeration of much thinner flakes. The agglomeration of the rGO might be due to edge to edge interactions between oxygen functional groups via hydrogen bonding [17]. We can also observe a small number of carbon spheres that contain hydrophobic core and hydrophilic shell [38]. The average flake diameter of the sample observed is $200 \mathrm{~nm}$.

Hydrodynamic mean-size and size distributions of sample dispersion were studied by Dynamic Light Scattering (DLS) technique (Fig. 3). The mean hydrodynamic thickness of the sample is $654.2 \mathrm{~nm}$ with the polydispersity index of 0.005 . Further, the stability of the sample in a colloidal solution was determined by Zeta potential analyzer. A moderate Zeta potential of $-27.40 \mathrm{mV}$ was observed for the sample, which may have resulted from the static

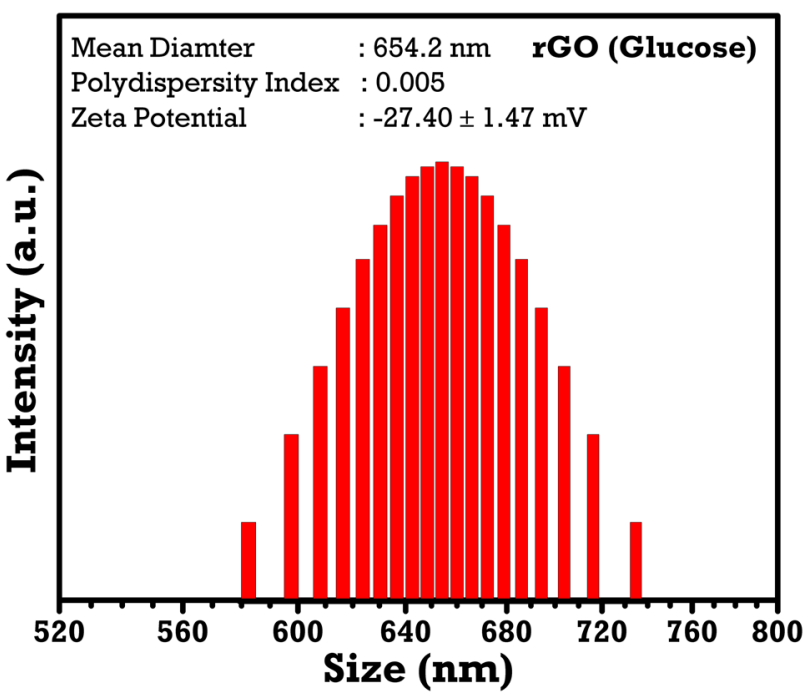

Fig. 3 Hydrodynamic size distributions and Zeta potential of carbonyl-rich partially reduced graphene oxide repulsive force developed due to the presence of negatively charged oxygen functional groups on the surface and along the edges [17]. This suggests that the present sample can be used in biomedical and water treatment related applications.

\section{Reaction mechanism}

Glucose, when hydrothermally treated transforms into carbonyl-rich graphene oxide through carbonization [39] and subsequently gets reduced into carbonyl-rich partially reduced graphene oxide (Fig. 4).

\subsection{Carbonyl-rich graphene oxide formation}

Carbonization takes place mainly via three steps (1) Dehydration and Fragmentation, (2) Polymerization/Condensation and (3) Aromatization.

\subsubsection{Dehydration and fragmentation of glucose into soluble products}

Under the hydrothermal condition, glucose converts into 5-Hydroxymethylfurfural (5-HMF) through dehydration reaction [40]. 5-HMF further converts to $1,2,4$ benzenetriol [41], erythrose [42], 2,5-dioxo-6-hydroxy hexanol [43], furfural [44], and glyceraldehyde [42]. Then, these products partially decompose into acids, aldehydes, and phenols via. ring opening and $\mathrm{C}-\mathrm{C}$ bond breaking [45].

\subsubsection{Polymerization/condensation of the soluble products}

5-HMF and its decomposition products undergo polymerization via intermolecular dehydration or aldol addition/ condensation $[24,43,46]$. The acids produced in the previous step accelerates the polymerization process by making the reaction medium slightly acidic.

\subsubsection{Aromatization of the polymers, nucleation, and growth}

The polymers undergo aromatization via ring substitution and ring fusion reactions [44]. When the concentration of aromatic clusters in the aqueous solution reaches the critical supersaturation point, burst nucleation takes place [47]. The nuclei so formed grow outwards by diffusion and linkage [48] to form graphene oxide.

As observed from the FTIR and XPS spectra, the synthesized $\mathrm{rGO}$ contains a high amount of $\mathrm{C}=\mathrm{O}$ functional groups along with an aromatic $\mathrm{C}=\mathrm{C}$ carbon network. $\mathrm{C}=\mathrm{O}$ functional 


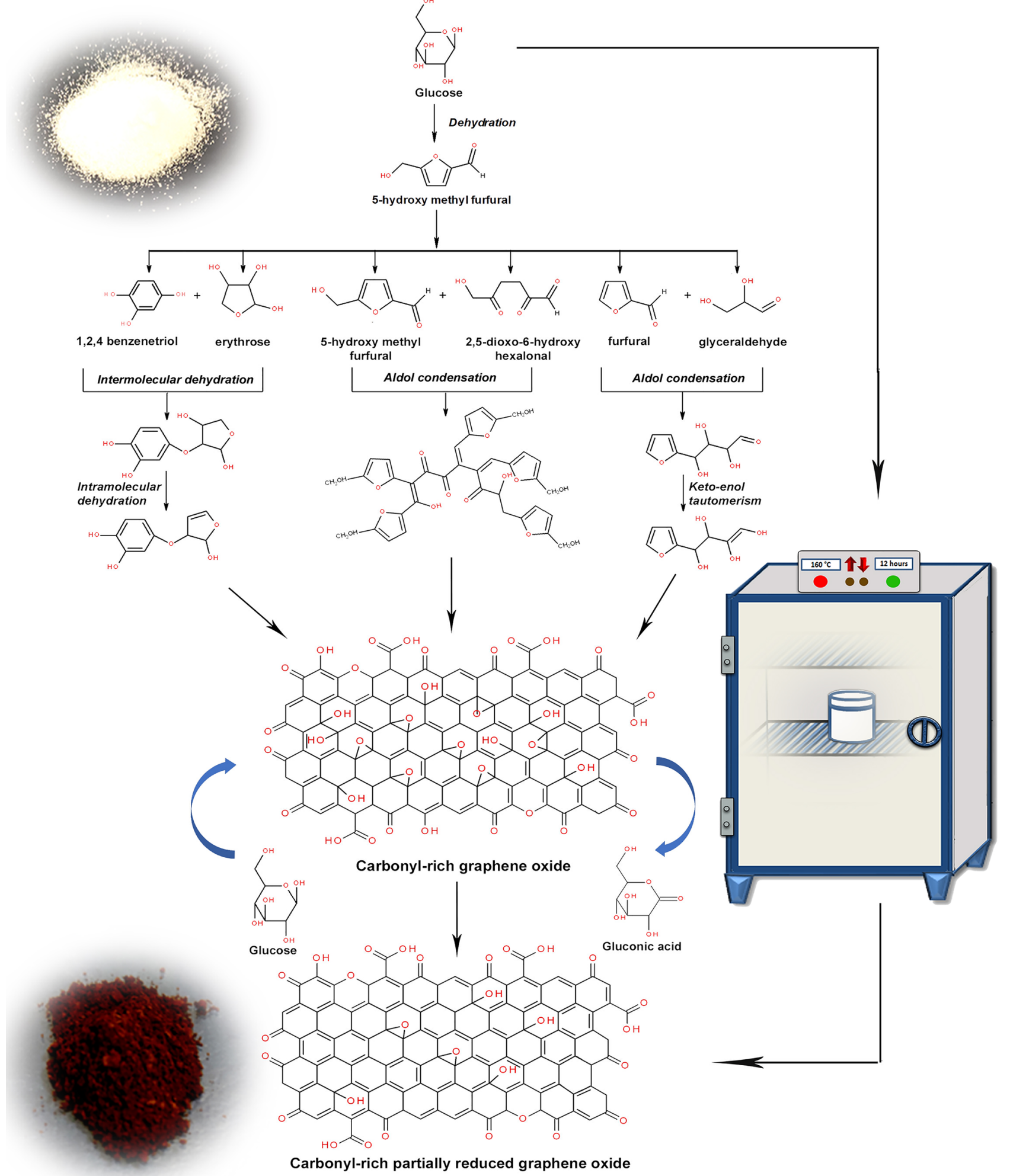

Fig. 4 Mechanism of formation of carbonyl-rich partially reduced graphene oxide from glucose 
group forms due to dehydration of equatorial hydroxyl groups. Whereas, $\mathrm{C}=\mathrm{C}$ network results from keto-enol tautomerism of the dehydrated species or via intramolecular dehydration [49].

\subsection{Reduction of carbonyl-rich graphene oxide}

Unutilized glucose in the solution acts as reducing agent during graphene oxide reduction. Glucose reacts with hydroxyl and epoxy groups on the basal plane of graphene oxide and gets oxidized to gluconic acid [22, 23]. Moreover, hydrothermal reduction itself preferentially reduce carbon single-bonded oxygen functional groups i.e. $\mathrm{O}-\mathrm{H}$ and $\mathrm{C}-\mathrm{O}-\mathrm{C}$ [33]. Therefore, the carbonyl functional groups $(C=O)$ remain unreduced during reduction and hence results in production of carbonyl-rich partially reduced graphene oxide.

\section{Conclusion}

In the present study, we synthesized carbonyl-rich partially reduced graphene oxide using glucose by hydrothermal method. The as-prepared sample was characterized by XRD, XPS, FTIR, UV-Vis, Raman, SEM, and DLS techniques. The sample contains 2-3-layers and has an interlayer spacing of $3.95 \mathrm{~A}^{\circ}$ and it contains a high amount of carbonyl functional groups at the plane edge. $\mathrm{C} / \mathrm{O}$ and $\mathrm{I}_{\mathrm{D}} / \mathrm{I}_{\mathrm{G}}$ ratio of the sample is 2.1 and 1.39, respectively. It has flake-like structure and hydrodynamic size $654.2 \mathrm{~nm}$ with a moderate zeta potential of $-27.40 \mathrm{mV}$. We also proposed a plausible reaction mechanism for the formation of carbonyl-rich partial reduced graphene oxide to provide insight into the structural evolution. The present work offers a simple, one-step, cost-effective and eco-friendly method for the mass production of carbonyl-rich partially reduced graphene oxide. The presence of peripheral carbonyl groups supports further functionalization and also improves the water dispersibility of the rGO samples which makes them useful candidates for biomedical and water treatment related applications.

Acknowledgements The authors thank KSTEPS, DST, Government of Karnataka for providing fellowship to the first author during the work. The authors would like to acknowledge the usage of XPS, DLS, and Raman facilities at IISc, Bengaluru, through INUP organized by MeitY, Gol and XRD facility at Department of Physics, Mangalore University established by DST-FIST. Authors would also like to thank Mr. Mahanthesha B. K. for providing assistance in preparing the manuscript and Mr. Kaushik B. R. for helping in plotting the reaction mechanism scheme.

\section{Compliance with ethical standards}

Conflict of interest The authors declare that they have no known competing financial interests or personal relationships that could have appeared to influence the work reported in this paper.

\section{References}

1. Dimiev AM, Tour JM (2014) Mechanism of graphene oxide formation. ACS Nano 8:3060-3068. https://doi.org/10.1021/nn500 $606 a$

2. Singh RK, Kumar R, Singh DP (2016) Graphene oxide: strategies for synthesis, reduction and frontier applications. RSC Adv 6:64993-65011. https://doi.org/10.1039/c6ra07626b

3. Thakur S, Karak N (2015) Alternative methods and nature-based reagents for the reduction of graphene oxide-a review. Carbon NY. https://doi.org/10.1016/j.carbon.2015.06.030

4. Lee S, Eom SH, Chung JS, Hur SH (2013) Large-scale production of high-quality reduced graphene oxide. Chem Eng J 233:297304. https://doi.org/10.1016/j.cej.2013.08.050

5. Mahmoudian L, Rashidi A, Dehghani H, Rahighi R (2016) Single-step scalable synthesis of three-dimensional highly porous graphene with favorable methane adsorption. Chem Eng J 304:784-792. https://doi.org/10.1016/j.cej.2016.07.015

6. He H, Klinowski J, Forster M, Lerf A (1998) A new structural model for graphite oxide. Chem Phys Lett 287:53-56. https:// doi.org/10.1016/S0009-2614(98)00144-4

7. Banhart F, Kotakoski J, Krasheninnikov AV (2011) Structural defects in graphene. ACS Nano 5:26-41. https://doi. org/10.1021/nn102598m

8. Gurunathan S, Woong Han J, Eppakayala V, Kim J (2013) Green synthesis of graphene and its cytotoxic effects in human breast cancer cells. Int J Nanomedicine 8:1015. https://doi.org/10.2147/ IJN.S42047

9. Upadhyay RK, Soin N, Bhattacharya G et al (2015) Grape extract assisted green synthesis of reduced graphene oxide for water treatment application. Mater Lett 160:355-358. https://doi. org/10.1016/j.matlet.2015.07.144

10. Bhattacharya G, Sas S, Wadhwa S et al (2017) Aloe vera assisted facile green synthesis of reduced graphene oxide for electrochemical and dye removal applications. RSC Adv 7:2668026688. https://doi.org/10.1039/c7ra02828h

11. Wang C, Han X, Xu P et al (2011) The electromagnetic property of chemically reduced graphene oxide and its application as microwave absorbing material. Appl Phys Lett 98:2011-2014. https://doi.org/10.1063/1.3555436

12. Zhu Y, Hengxing Ji H-MC, Ruoff RS (2018) Mass production and industrial applications of graphene materials. Natl Sci Rev 5:90-101

13. Guex LG, Sacchi B, Peuvot KF et al (2017) Experimental review: chemical reduction of graphene oxide (GO) to reduced graphene oxide ( $\mathrm{rGO}$ ) by aqueous chemistry. Nanoscale 9:95629571. https://doi.org/10.1039/c7nr02943h

14. Chua CK, Pumera M (2014) Chemical reduction of graphene oxide: a synthetic chemistry viewpoint. Chem Soc Rev 43:291312. https://doi.org/10.1039/c3cs60303b

15. Oliveira AEF, Braga GB, Tarley CRT, Pereira AC (2018) Thermally reduced graphene oxide: synthesis, studies and characterization. J Mater Sci 53:12005-12015. https://doi.org/10.1007/s1085 3-018-2473-3

16. Díez N, Śliwak A, Gryglewicz S et al (2015) Enhanced reduction of graphene oxide by high-pressure hydrothermal treatment. RSC Adv 5:81831-81837. https://doi.org/10.1039/C5RA14461B

17. Huang H, De Silva KKH, Kumara GRA, Yoshimura M (2018) Structural evolution of hydrothermally derived reduced graphene oxide. Sci Rep 8:6849. https://doi.org/10.1038/s41598-01825194-1

18. Liu X, Zheng M, Xiao K et al (2014) Simple, green and high-yield production of single- or few-layer graphene by hydrothermal exfoliation of graphite. Nanoscale 6:4598-4603. https://doi. org/10.1039/C3NR06219H 
19. Bayat A, Saievar-Iranizad E (2017) Synthesis of green-photoluminescent single layer graphene quantum dots: determination of HOMO and LUMO energy states. J Lumin 192:180-183. https ://doi.org/10.1016/j.jlumin.2017.06.055

20. Adel M, El-Maghraby A, El-Shazly O et al (2016) Synthesis of few-layer graphene-like nanosheets from glucose: new facile approach for graphene-like nanosheets large-scale production. J Mater Res 31:455-467. https://doi.org/10.1557/jmr.2016.25

21. Tang L, Li X, Ji R et al (2012) Bottom-up synthesis of large-scale graphene oxide nanosheets. J Mater Chem 22:5676. https://doi. org/10.1039/c2jm15944a

22. Zhu C, Guo S, Fang Y, Dong S (2010) Reducing sugar: new functional molecules for the green synthesis of graphene nanosheets. ACS Nano 4:2429-2437. https://doi.org/10.1021/ nn1002387

23. Akhavan O, Ghaderi E, Aghayee S et al (2012) The use of a glucose-reduced graphene oxide suspension for photothermal cancer therapy. J Mater Chem 22:13773. https://doi. org/10.1039/c2jm31396k

24. Ryu J, Suh YW, Suh DJ, Ahn DJ (2010) Hydrothermal preparation of carbon microspheres from mono-saccharides and phenolic compounds. Carbon N Y 48:1990-1998. https://doi. org/10.1016/j.carbon.2010.02.006

25. Syama S, Mohanan PV (2019) Comprehensive application of graphene: emphasis on biomedical concerns. Springer, Berlin

26. Hatamie S, Akhavan O, Sadrnezhaad SK et al (2015) Curcuminreduced graphene oxide sheets and their effects on human breast cancer cells. Mater Sci Eng C 55:482-489. https://doi. org/10.1016/j.msec.2015.05.077

27. Yaragalla S, Rajendran R, Jose J et al (2016) Preparation and characterization of green graphene using grape seed extract for bioapplications. Mater Sci Eng C 65:345-353. https://doi. org/10.1016/j.msec.2016.04.050

28. Zhang RL, Duan JJ, Han Z et al (2020) One-step aqueous synthesis of hierarchically multi-branched PdRuCu nanoassemblies with highly boosted catalytic activity for ethanol and ethylene glycol oxidation reactions. Appl Surf Sci 506:144791. https://doi. org/10.1016/j.apsusc.2019.144791

29. Chen HY, Niu HJ, Ma X et al (2020) Flower-like platinum-cobaltruthenium alloy nanoassemblies as robust and highly efficient electrocatalyst for hydrogen evolution reaction. J Colloid Interface Sci 561:372-378. https://doi.org/10.1016/j.jcis.2019.10.122

30. Abdolhosseinzadeh S, Asgharzadeh H, Seop Kim H (2015) Fast and fully-scalable synthesis of reduced graphene oxide. Sci Rep 5:10160. https://doi.org/10.1038/srep10160

31. Ganguly A, Sharma S, Papakonstantinou P, Hamilton J (2011) Probing the thermal deoxygenation of graphene oxide using high-resolution in situ X-ray-based spectroscopies. J Phys Chem C 115:17009-17019. https://doi.org/10.1021/jp203741y

32. Mahata S, Sahu A, Shukla P et al (2018) The novel and efficient reduction of graphene oxide using Ocimum sanctum $L$. leaf extract as an alternative renewable bio-resource. New J Chem 42:19945-19952. https://doi.org/10.1039/C8NJ04086A

33. Zhou Y, Bao Q, Tang LAL et al (2009) Hydrothermal dehydration for the "green" reduction of exfoliated graphene oxide to graphene and demonstration of tunable optical limiting properties. Chem Mater 21:2950-2956. https://doi.org/10.1021/cm9006603

34. Tiwari SK, Nimbalkar AS, Hong CK, Ha SK (2019) A green route for quick and kilogram production of reduced graphene oxide and their applications at low loadings in epoxy resins. ChemistrySelect 4:1266-1274. https://doi.org/10.1002/slct.201803792
35. Wang J, Salihi EC, Šiller L (2017) Green reduction of graphene oxide using alanine. Mater Sci Eng C 72:1-6. https://doi. org/10.1016/j.msec.2016.11.017

36. Shi YC, Feng JJ, Lin XX et al (2019) One-step hydrothermal synthesis of three-dimensional nitrogen-doped reduced graphene oxide hydrogels anchored PtPd alloyed nanoparticles for ethylene glycol oxidation and hydrogen evolution reactions. Electrochim Acta 293:504-513. https://doi.org/10.1016/j.elect acta.2018.10.068

37. Wu J-B, Lin M-L, Cong X et al (2018) Raman spectroscopy of graphene-based materials and its applications in related devices. Chem Soc Rev 47:1822-1873. https://doi.org/10.1039/C6CS0 0915H

38. Li R, Wang L, Shahbazi A (2015) A review of hydrothermal carbonization of carbohydrates for carbon spheres preparation. Trends Renew Energy 1:43-56. https://doi.org/10.17737/ tre.2015.1.1.009

39. Poerschmann J, Weiner B, Koehler R, Kopinke F-D (2017) Hydrothermal carbonization of glucose, fructose, and xylose-identification of organic products with medium molecular masses. ACS Sustain Chem Eng 5:6420-6428. https://doi.org/10.1021/ acssuschemeng.7b00276

40. Scallet BL, Gardner JH (1945) Formation of 5-hydroxymethylfurfural from D-glucose in aqueous solution 1. J Am Chem Soc 67:1934-1935. https://doi.org/10.1021/ja01227a017

41. Luijkx GCA, van Rantwijk F, van Bekkum H (1993) Hydrothermal formation of 1,2,4-benzenetriol from 5-hydroxymethyl-2-furaldehyde and D-fructose. Carbohydr Res 242:131-139. https://doi. org/10.1016/0008-6215(93)80027-C

42. Möller M, Nilges $P$, Harnisch F, Schröder U (2011) Subcritical water as reaction environment: fundamentals of hydrothermal biomass transformation. Chemsuschem 4:566-579. https://doi. org/10.1002/cssc.201000341

43. Patil SKR, Lund CRF (2011) Formation and growth of humins via aldol addition and condensation during acid-catalyzed conversion of 5-hydroxymethylfurfural. Energy Fuels 25:4745-4755. https://doi.org/10.1021/ef2010157

44. Chuntanapum A, Matsumura Y (2009) Formation of tarry material from 5-HMF in subcritical and supercritical water. Ind Eng Chem Res 48:9837-9846. https://doi.org/10.1021/ie900423g

45. Ogihara $Y$, Smith RL, Inomata H, Arai K (2005) Direct observation of cellulose dissolution in subcritical and supercritical water over a wide range of water densities $\left(550-1000 \mathrm{~kg} / \mathrm{m}^{3}\right)$. Cellulose 12:595-606. https://doi.org/10.1007/s10570-005-9008-1

46. Sevilla M, Fuertes AB (2009) The production of carbon materials by hydrothermal carbonization of cellulose. Carbon $\mathrm{N} \mathrm{Y}$ 47:2281-2289. https://doi.org/10.1016/j.carbon.2009.04.026

47. La MV (1952) Nucleation in phase transitions. Ind Eng Chem 44:1270-1277. https://doi.org/10.1021/ie50510a027

48. LaMer VK, Dinegar RH (1950) Theory, production and mechanism of formation of monodispersed hydrosols. J Am Chem Soc 72:4847-4854. https://doi.org/10.1021/ja01167a001

49. Tang MM, Bacon R (1964) Carbonization of cellulose fibers I low temperature pyrolysis. Carbon N Y 1:390. https://doi. org/10.1016/0008-6223(64)90415-4

Publisher's Note Springer Nature remains neutral with regard to jurisdictional claims in published maps and institutional affiliations. 